\title{
Optical Analysis Authenticated Electrical Impedance Based Quantification of Aqueous Naphthalene
}

\author{
Shramana Roy Barman', Subhadip Chakraborty², Aniruddha Mukhopadhyay ${ }^{1}$, Sanatan \\ Chattopadhyay ${ }^{2 *}$
}

${ }^{1}$ Department of Environmental Science, University of Calcutta, 35 Ballygunge Circular Road, Kolkata 700019, India

${ }^{2}$ Department of Electronic Science, University of Calcutta, 92A.P.C. Road, Kolkata 700009, India

Graphical Abstract

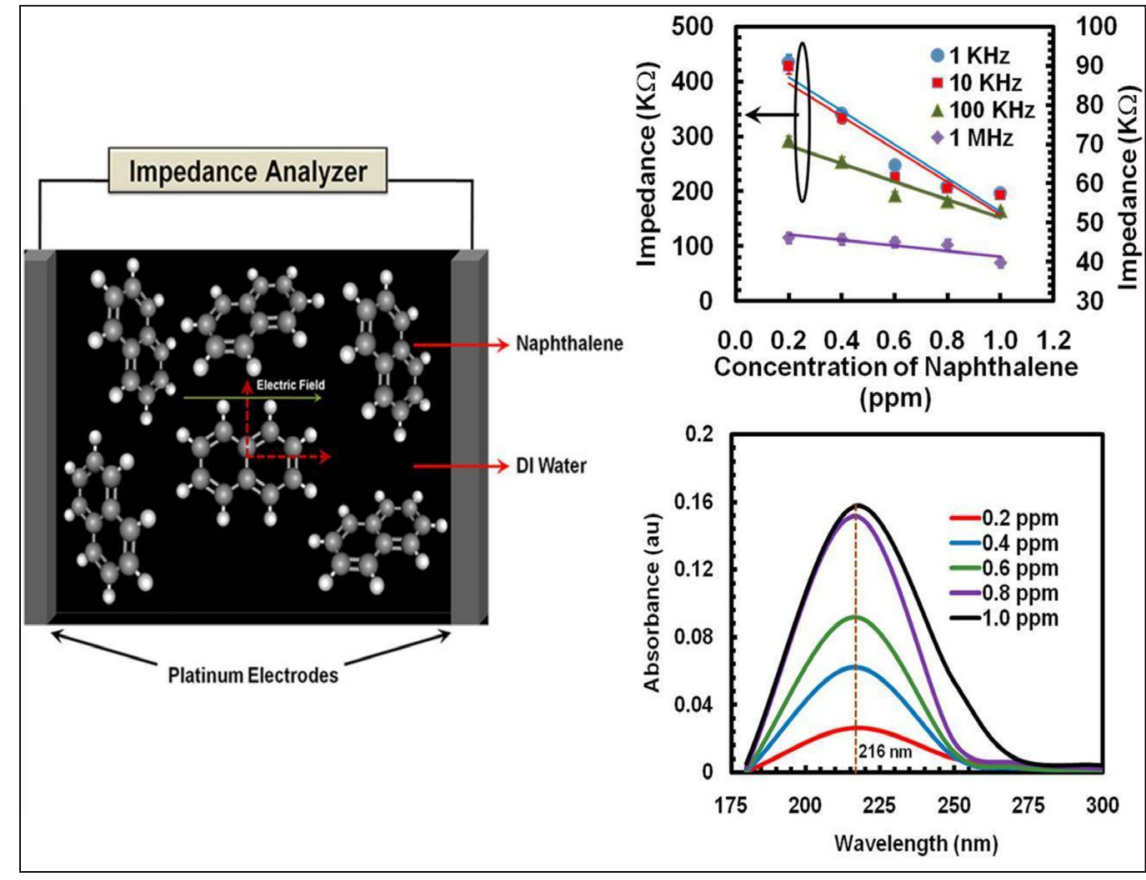

Schematic representation of the system under investigation and variation of its electrical and optical properties with varying concentration of naphthalene.

Polyaromatic hydrocarbons (PAH) are organic compounds with fused benzene rings that have toxic and mutagenic properties, and have been well documented for their detrimental effect on animal and plant health. Naphthalene, a two-ring $\mathrm{PAH}$, is a common water pollutant which has been linked to the disruption of immune system as well as deformation of red blood corpuscles in human and thereby raising substantial concerns. The present study quantitatively estimates naphthalene in its aqueous solution by employing electrical impedance spectroscopy (EIS), which is simultaneously supported by UV-vis spectral analysis. Naphthalene solutions of varying concentrations (0.2-1 ppm) are prepared and subjected to EIS as well as UV-visible spectroscopy. For the EIS based studies, the data is recorded for the frequency range of $1 \mathrm{KHz}-1 \mathrm{MHz}$ and electrical parameters such as capacitance, conductance and admittance are observed to increase from $3.5 \mathrm{pF}-7.2 \mathrm{pF}, 2.3 \mu \mathrm{S}-6.1 \mu \mathrm{S}$ and $2.4 \mu \mathrm{S}-27.3 \mu \mathrm{S}$, 
respectively, with varying naphthalene concentration in its solution. On the other hand impedance values are observed to decrease with the same. Naphthalene is itself a non-polar molecule and the formation of instantaneous dipoles originating from the interaction of such molecules governs the overall dielectric nature of the solution. UV-vis spectroscopic measurements of the solutions reveal the characteristic absorbance maxima at $216 \mathrm{~nm}$ for all the concentrations under investigation. Absorbance values are observed to increase with the relative strength of naphthalene in the solution and such values vary in the range of $0.02-0.16$ au for the peak obtained. Thus by corroborating the electrical and the optical parameters, this study establishes a quick and handy method for detection of naphthalene in aqueous solutions and ascertains a framework for further work that can be done to formulate a naphthalene sensing device.

Keywords: Naphthalene, electrical impedance spectroscopy, instantaneous dipoles, UV-vis spectral analysis, system energy.

\section{INTRODUCTION}

Global industrialization has triggered a large scale abuse of natural resources and chemicals over the last few decades. This rapid development and commercialization have resulted in extensive pollution of water bodies in and around the industrial areas and cities since the dumping of toxic waste into water bodies is a common malpractice. This pollution of water bodies has become a prominent environmental issue due to the ever increasing demand for potable water, especially in heavily populated cities. Trace amount of compounds like pesticides, dyes, phenols surfactant, polyaromatic hydrocarbons, heavy metals etc. have been often found in drinking water [1-4].

Polyaromatic hydrocarbons (PAHs) constitute a group of organic compounds that contain two or more fused aromatic ring in their chemical structure [5]. They are environmentally persistent and their structure ranges from simple naphthalene to complex coronene with varying extent of toxicity [6].

PAHs are generally released into the environment due to the incomplete combustion of fossil fuels, improper disposal of waste, burning of tobacco and plastics, extensive use of pesticides etc. [7]. The infusion of these compounds into water bodies is attributed to oil spillage accidents, discharges from various industries, wet and dry atmospheric fallouts and surface runoff [5]. PAHs can easily form associates with various suspended particles within the aquatic system and thus become persistent, enabled of bio-magnification [8]. Most of the PAHs are sparingly soluble in water and thus form bio recalcitrant and persist in the environment for a long time. PAHs have been scheduled by various government agencies as pollutants of prime concern [9]. PAHs have been proven to be toxic, carcinogenic as well as mutagenic in nature and can act as potential immunosuppressant. Due to their lipophilic nature PAHs can easily penetrate the cell membrane altering their morphology and can interfere with enzyme activity. It has also been proven that PAHs can have detrimental effect on the humoral immunity $[6,10]$. Naphthalene is one of the most common PAHs discharged in the environment [11]. It is a simple two-ringed structure which has been linked to reduced immunity and destruction of red blood cells. Naphthalene reportedly can also disrupt functions of the cell membrane and interfere with enzyme functions [12]. Owing to its hazardous characteristics the United States Environmental Protection Agency has restricted the maximum PAH level in drinking water to be $0.2 \mathrm{ppb}$ [13]. However, the discharge and level of various PAHs often go undetected and PAH level as high as $1.5 \mathrm{ppm}$ has also been reported by previous studies [14].

Considering the hazardous impact posed by naphthalene on human health, the removal of the same from waste water using various methodologies is of primary concern. A vital step prior to the removal of naphthalene is its detection. Various biomarkers have been used to detect different PAHs in aquatic and marine organisms such as mussels, Atlantic cods, brown trout, bivalves etc. [15-17]. Traditional methods such as gas chromatography, mass spectrometry, capillary electrophoresis etc. for detecting aqueous PAH cannot be performed on site which is the need of the hour. Recently, a substantial amount 
of research is focused on onsite quick detection of PAHs in water. Electrochemical techniques such as formulation of self-assembled monolayer for detection of pyrene [18], fabrication of cadmium/aluminum layered electrodes for detection of anthracene [19] as well as preparation of polymer based molecularly imprinted sensors coupled with fluorescence and mass-sensitive transducers for the detection of PAHs [20] have been carried out in recent past. However amongst all other techniques, impedance spectroscopy has flourished as a potential contender in analytical measurements since last decade [21] due to its rapid turn out, simplicity and cost-effectiveness. In electrical impedance spectroscopy, several electrical parameters such as impedance, capacitance, reactance and conductance are monitored with a frequency sweep. The changes in these parameters are attributed to the variation of effective dielectric constant of the system caused by density gradient of the analyte to be estimated qualitatively or quantitatively.

The present study elucidates the quantitative estimation of naphthalene, a common urban water pollutant, using electrical impedance spectroscopy. Dielectric analysis, being the pivotal factor for such technique, is rigorously studied in this work considering the formation of instantaneous dipole moment of naphthalene which is inherently non-polar in nature. The electrical data thus generated have been supported optically by spectrophotometric analysis. This is the first known attempt towards designing a system for rapid electrical detection of naphthalene from its solution.

\section{MATERIALS AND METHODS \\ Chemicals used}

The naphthalene $\left(\mathrm{C}_{10} \mathrm{H}_{8}\right)$ used for the present study has been procured from Merck, India. The other chemicals used were of analytical grade and obtained from the same.

\section{Sample preparation}

Stock solution of $1.0 \mathrm{ppm}$ naphthalene was prepared using distilled water and further dilutions of 0.2 ppm, 0.4 ppm, $0.6 \mathrm{ppm}$ and $0.8 \mathrm{ppm}$ were prepared just before conducting the experiments.

\section{Spectrophotometric analysis}

Spectrophotometric analysis of the sample is performed by using a UV-vis spectrophotometer (LAMBDA 1050 UV/VIS/INR) [22]. Samples are scanned from $170 \mathrm{~nm}$ to $500 \mathrm{~nm}$ using a quartz cuvette of path length $10 \mathrm{~mm}$. The optical densities (ODs) are recorded and used for data analysis. From the Beer Lambert's law the molar absorption coefficient can be calculated using the Equation (1):

$$
A=\varepsilon \mathrm{cl}
$$

where, $A$ represents absorbance value, $\varepsilon$ is the molar absorptivity coefficient $\left(\mathrm{L} \mathrm{mol}^{-1} \mathrm{~cm}^{-1}\right), \mathrm{c}$ represents concentration $\left(\mathrm{mol} \mathrm{L}^{-1}\right)$ and $\mathrm{I}$ is the path length $(\mathrm{cm})$.

\section{Circuit analysis of the electrical measurement set-up}

The electrical measurement of the samples containing naphthalene in different strengths is performed using a computer-interfaced LCR meter (TEGAM, Model 3550), where a parallel-plate conductivity cell, with unity cell constant, is connected to the meter. The schematics of the experimental system and its electrical equivalent circuit are depicted in Figure 1. 


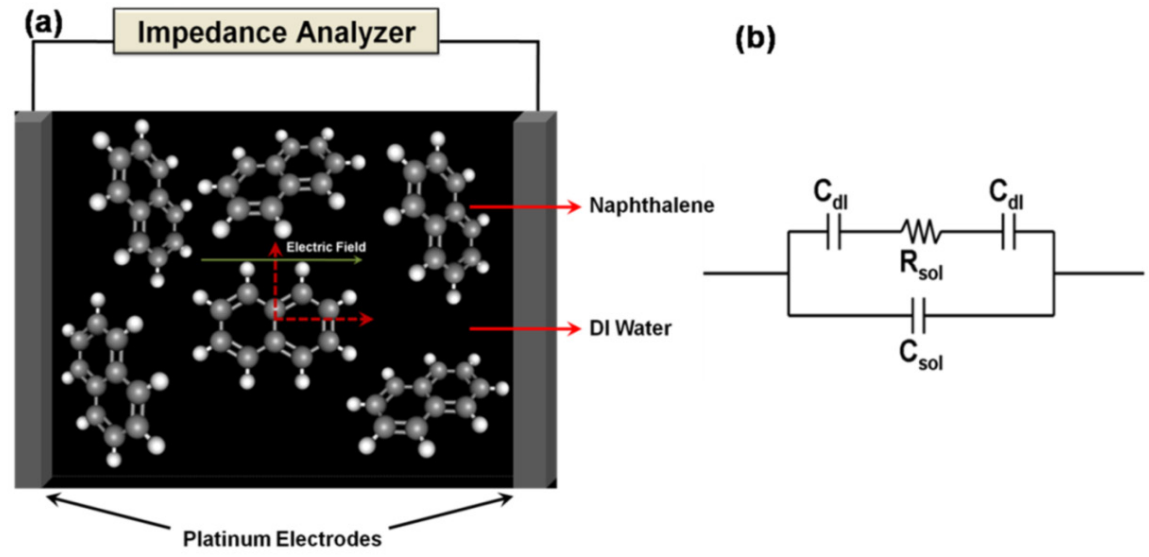

Figure 1. (a) Schematics of the experimental system and (b) its electrical equivalent circuit.

The equivalent circuit consists of two capacitors $\left(C_{d l}\right)$ and a resistor $\left(R_{\text {sol }}\right)$ in series and the third capacitor $\left(\mathrm{C}_{\mathrm{sol}}\right)$ is in parallel with the series combination, as depicted in Figure $1(\mathrm{~b}) . \mathrm{C}_{\mathrm{dl}}$ is associated with the parallel plates/electrodes and represents the double-layer capacitance on the surface of electrodes and the liquid. The dielectric nature of the solution contributes to the solution capacitance and resistance, represented by $\mathrm{C}_{\text {sol }}$ and $\mathrm{R}_{\text {sol }}$ respectively.

Electrical measurements are performed at an applied $\mathrm{AC}$ bias of $1 \mathrm{~V}$ amplitude (peak to peak) and the LCR meter is well-equipped with noise reduction techniques.

The capacitance of the system can be calculated using Equation (2):

$$
C=\frac{\left|\varepsilon^{*}\right| A}{d}
$$

where, $\varepsilon^{*}$ is the complex permittivity of the system, given by $\varepsilon^{*}=\varepsilon-j \sigma / 2 \pi f, \varepsilon$ and $\sigma$ being the real permittivity and the conductivity of the system and $f$ being the applied frequency on the system. $A$ and $d$ denote the electrode area and the distance between two electrodes, respectively. Here $j$ is the square root of negative one.

The equivalent impedance of such a circuit is given by Equations (3), (4) and (5):

$$
|Z|=\frac{\left|z_{1}\right| \cdot\left|z_{2}\right|}{\left|z_{1}+z_{2}\right|}
$$

where

$$
z_{1}=R_{\text {sol }}-\frac{j}{\pi f C_{d l}}
$$

$$
\text { and } \quad z_{2}=-\frac{j}{2 \pi f C_{s o l}}
$$

where $j$ is the square root of negative one

In such type of systems, double layer capacitors become significant at very low frequencies, resistive part and the dielectric part of the solution dominates at mid and relatively higher frequency ranges respectively [23-26]. 


\section{RESULTS AND DISCUSSION \\ Variation of electrical and optical parameters with relative strength of naphthalene in its aqueous solution}

Figures 2(a), (b), (c) and (d) represent the variation of impedance, capacitance, conductance and admittance, respectively with varying strength of naphthalene. It is apparent from the Figure 2 that the system impedance decreases with naphthalene concentration whereas capacitance, conductance and admittance are observed to increase with the same. Impedance values are observed to vary from 40 $\mathrm{k} \Omega$ to $436 \mathrm{k} \Omega$ for the frequency range $1 \mathrm{kHz}$ to $1 \mathrm{MHz}$ and the relevant capacitance and conductance values change from $3.5 \mathrm{pF}-7.2 \mathrm{pF}$ and $2.3 \mu \mathrm{S}-6.1 \mu \mathrm{S}$, respectively. For a fixed frequency, the increase of capacitance with naphthalene concentration is attributed to the formation of instantaneous dipole moment inside the system. Coefficient of regression $\left(R^{2}\right)$ values and line equations for the various measurements are summarized in Table I.

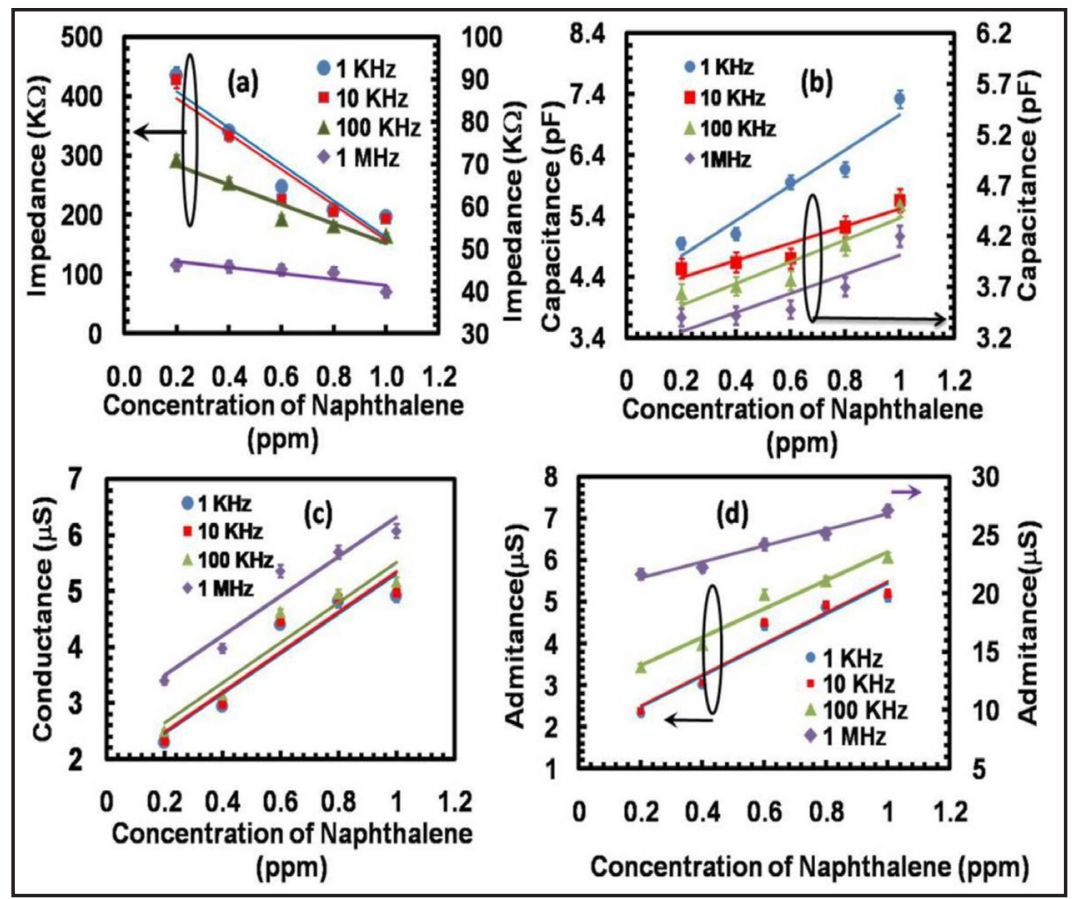

Figure 2. Variation of electrical parameters with relative strength of naphthalene in its aqueous solution; (a) represents variation in impedance; (b) depicts the variation of capacitance; (c) shows the variation conductance; and $(d)$ represents the variation admittance with varying strength of naphthalene.

Naphthalene is a non-polar molecule and exhibits London forces as a result of the correlated movements of the electrons as they interact with each other [27]. Electrons of the adjacent molecules always repel each other which results in the redistribution of electron density in a molecule [28]. Such redistribution of electron density consequently causes fluctuations in their polarity structure, and thereby forming instantaneous dipoles as illustrated in Figure 3. Spontaneous formation of a dipole induces a polarity in the neighboring molecules. Increment of the non-polar molecule concentration in the system enhances the formation of instantaneous dipoles and hence the net effective dipole moment of the system increases [18]. Such increase of net dipole moment augments the system polarization, and hence the effective permittivity of the solution under investigation, which consequently raises the capacitance of the system. 
Table I. Coefficient of regression $\left(R^{2}\right)$ values and line equations for the various measurements

\begin{tabular}{|c|c|c|c|c|}
\hline \multicolumn{5}{|c|}{ Impedance } \\
\hline & $1 \mathrm{KHz}$ & $10 \mathrm{KHz}$ & $100 \mathrm{KHz}$ & $1 \mathrm{MHz}$ \\
\hline $\begin{array}{l}\text { Coefficient of } \\
\text { regression }\end{array}$ & $R^{2}=0.9107$ & $R^{2}=0.8728$ & $\mathrm{R}^{2}=0.9276$ & $R^{2}=0.7633$ \\
\hline $\begin{array}{l}\text { Equation of } \\
\text { line }\end{array}$ & $\begin{array}{c}y=-3 E+5 x+ \\
46878\end{array}$ & $\begin{array}{c}y=-2.9 E+5 x+ \\
45583\end{array}$ & $\begin{array}{c}y=-1.6 E+5 x+ \\
31620\end{array}$ & $\begin{aligned} y= & -0.7 E+5 x+ \\
& 4848.6\end{aligned}$ \\
\hline \multicolumn{5}{|c|}{ Capacitance } \\
\hline $\begin{array}{l}\text { Coefficient of } \\
\text { regression }\end{array}$ & $R^{2}=0.9295$ & $R^{2}=0.8846$ & $R^{2}=0.8733$ & $R^{2}=0.785$ \\
\hline $\begin{array}{l}\text { Equation of } \\
\text { line }\end{array}$ & $\begin{array}{c}y=3 E-13 x+ \\
4 E-12\end{array}$ & $\begin{array}{c}y=8 E-14 x+ \\
4 E-12\end{array}$ & $\begin{array}{c}y=1 E-13 x+ \\
3 E-12\end{array}$ & $\begin{array}{c}y=9 E-14 x+ \\
3 E-12\end{array}$ \\
\hline \multicolumn{5}{|c|}{ Conductance } \\
\hline $\begin{array}{l}\text { Coefficient of } \\
\text { regression }\end{array}$ & $R^{2}=0.8998$ & $R^{2}=0.9011$ & $R^{2}=0.9101$ & $R^{2}=0.9385$ \\
\hline $\begin{array}{l}\text { Equation of } \\
\text { line }\end{array}$ & $\begin{array}{c}y=3.54 \mathrm{E}-07 x+ \\
1.7 \mathrm{E}-06\end{array}$ & $\begin{array}{c}y=3.57 \mathrm{E}-07 x+ \\
1.8 \mathrm{E}-06\end{array}$ & $\begin{array}{c}y=3.56 \mathrm{E}-07 \mathrm{x}+ \\
1.9 \mathrm{E}-06\end{array}$ & $\begin{aligned} y= & 3.52 E-07 x+ \\
& 2.7 E-06\end{aligned}$ \\
\hline \multicolumn{5}{|c|}{ Admittance } \\
\hline $\begin{array}{l}\text { Coefficient of } \\
\text { regression }\end{array}$ & $R^{2}=0.929$ & $R^{2}=0.930$ & $R^{2}=0.9644$ & $R^{2}=0.9719$ \\
\hline $\begin{array}{l}\text { Equation of } \\
\text { line }\end{array}$ & $\begin{array}{c}y=4 \mathrm{E}-07 x+ \\
2 E-06\end{array}$ & $\begin{array}{c}y=3.7 E-07 x+ \\
1.7 E-06\end{array}$ & $\begin{array}{c}\mathrm{y}=3.4 \mathrm{E}-07 \mathrm{x}+ \\
2.8 \mathrm{E}-06\end{array}$ & $\begin{array}{c}y=7 \mathrm{E}-07 \mathrm{x}+ \\
2 \mathrm{E}-05\end{array}$ \\
\hline
\end{tabular}

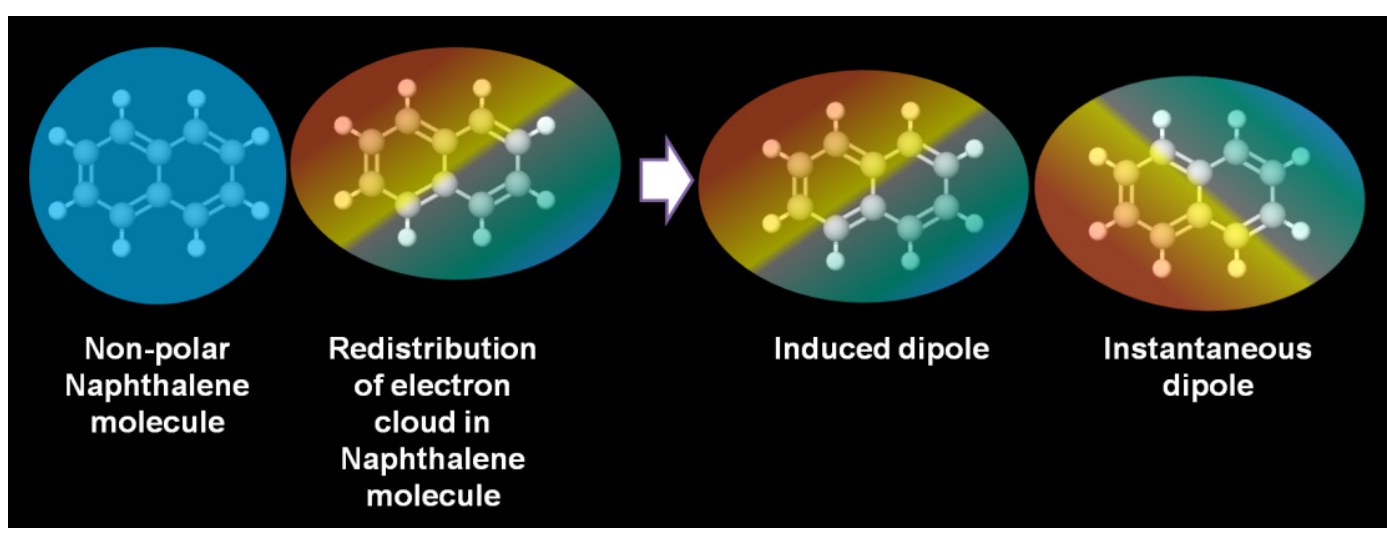

Figure 3. Redistribution of electron cloud in naphthalene molecule and instantaneous dipole and induced dipole.

Dielectric constant or relative permittivity is a fundamental property of a system depending upon its constituents. Capacitance is directly proportional to dielectric constant for a fixed geometrical dimension of the measuring system. Impedance is a complex parameter which depends upon the internal reactance (or, the capacitive impedance) due to the capacitance. Increment in capacitance consequently lowers the capacitive reactance and hence the impedance of the system. Admittance and 
conductance are inversely proportional to the system impedance, and hence exhibit incremental trends with increasing naphthalene concentration.

UV-vis spectroscopic measurements are performed on the samples with varying naphthalene concentration of $0.2-1.0 \mathrm{ppm}$ and plotted in Figure 4. A peak is obtained at $216 \mathrm{~nm}$ for all the concentrations of naphthalene observed from the plots. Absorbance values are observed to increase with the relative strength of naphthalene in the solution and such values vary in the range of $0.02-0.16$ au for the peak obtained. This increment can be attributed to the increased amount of capacity of the system to absorb light in the UV-vis spectral region with addition of naphthalene content in the solution. It is apparent from the figures that the nature of variation of the experimentally obtained absorbance values follows the Beer-Lambert law.
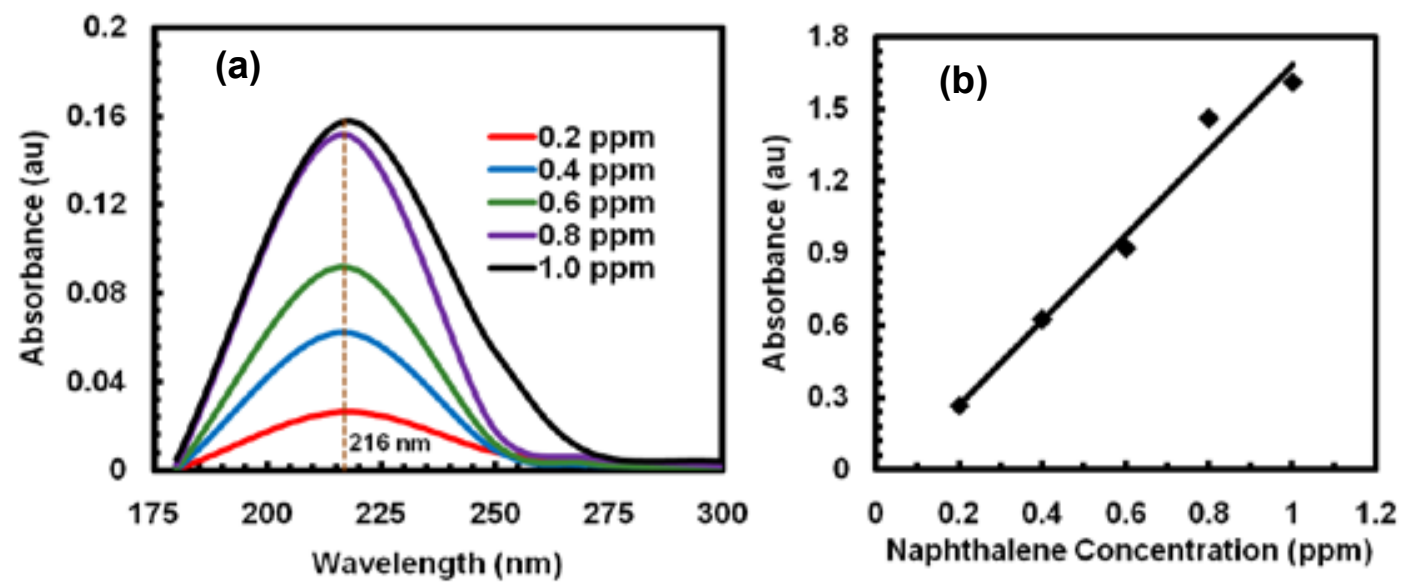

Figure 4. (a) UV absorbance spectrum of naphthalene solutions of different strengths; (b) Variation of absorbance with varying naphthalene concentration.

As discussed earlier, formation of instantaneous dipoles inside the system increases with the addition of naphthalene, which in turn enhances the effective polarization and hence the randomness of the system. Consequently, system entropy and thereby the internal energy of the system get increased. UV-vis spectral analysis confirms increment of absorbance with compositional variation of naphthalene, and thus indicates an increase in the total absorbed energy of the system which corroborates the physical observation from the dielectric study of the system with varying strength of naphthalene.

\section{Determination of the coefficient of sensitivity}

The slope of the curve as shown in Figure 2(a) describes the change in impedance for a variation of naphthalene concentration of a unit ppm. Hence, a factor in terms of impedance may be defined to signify the sensitivity of the system:

$$
\beta=\frac{\sum(m-\bar{m})(Z-\bar{Z})}{\sum(m-\bar{m})^{2}}
$$

where, $m$ and $Z$ indicate the naphthalene concentration and impedance of the system respectively. The bar operator on $m$ and $Z$ gives their respective average values for all relevant experimental data available. Figure 5 depicts coefficient of sensitivity of the present measurement system, calculated by using Equation (6), for the frequencies under consideration. It is apparent from the figure that coefficient of sensitivity decreases with the frequency of external electric field applied to the system. 


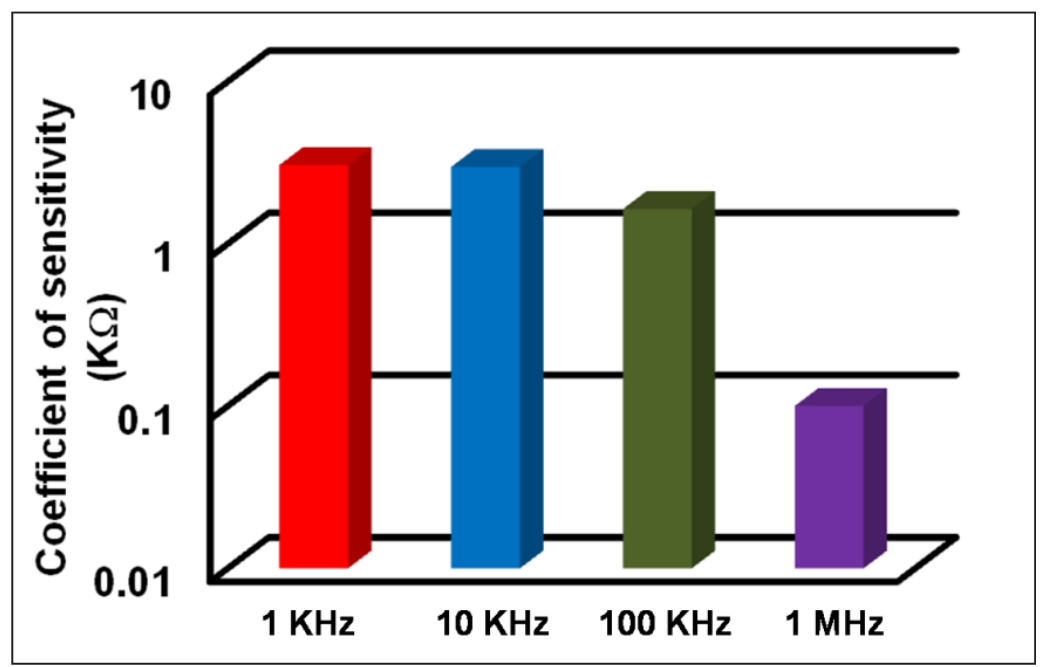

Figure 5. Plots showing the coefficients of sensitivity in terms of impedance for the frequencies under consideration.

\section{Statistical analysis}

All the experiments are performed thrice a day for three days and the data is represented as mean \pm standard deviation (SD). Microsoft Excel 2007 is used for calculations and analysis of data. The measured data displayed uncertainty of $\leq 2 \%$.

\section{Electrode stability}

To evaluate the stability of the measuring system, impedance values relevant to a fixed naphthalene concentration $(0.2 \mathrm{ppm})$ and frequency $(1 \mathrm{KHz})$ are measured for three days at an interval of one day to ensure the reproducibility of the electrode performance. It has been observed that the impedance values exhibit a variation in activity only by $1.5 \%$ and there by justify the robustness of the experimental system. Figure 6 shows the relevant impedance values for three days.

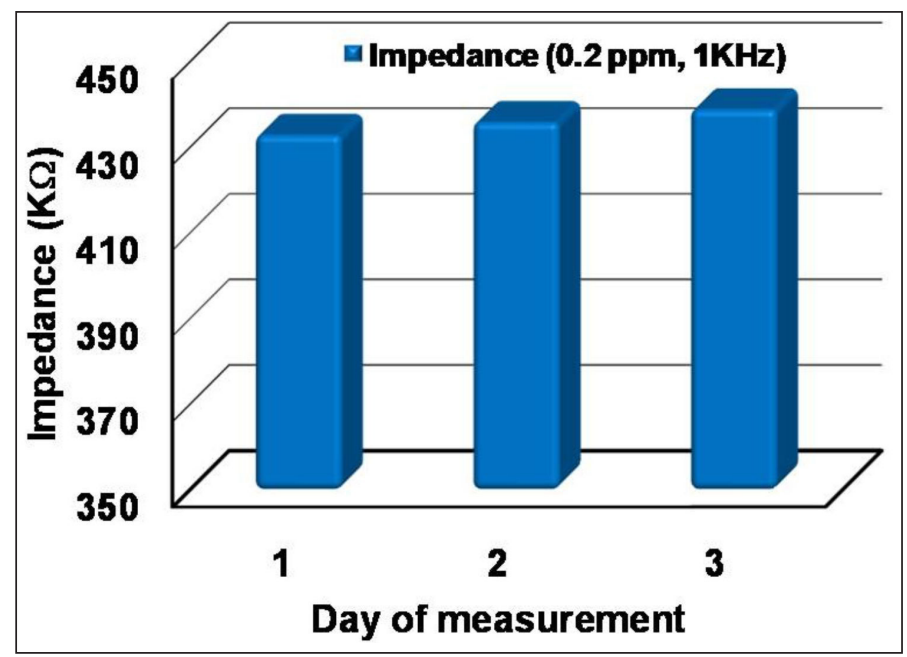

Figure 6. Plots of the impedance values corresponding to a fixed naphthalene concentration $(0.2 \mathrm{ppm})$ and frequency $(1 \mathrm{KHz})$ measured for three days. 


\section{CONCLUSIONS}

Electrical parameters including the impedance, admittance, capacitance and conductance of naphthalene solution of varying strength are measured by employing impedance spectroscopy in this study. Formation of instantaneous dipoles in the system is observed to govern the effective dielectric behavior of the naphthalene solution. Spontaneous formation of a dipole induces a polarity in the neighboring non-polar constituent molecules. Increment of the non-polar molecule concentration in the system augments the formation of instantaneous dipoles and hence the effective dipole moment of the system increases. Coefficient of sensitivity in terms of impedance is also calculated for the measuring system, from which a decent change in impedance is observed for a variation of naphthalene concentration of a unit ppm. Spectrophotometric analyses of the solutions are also conducted and a prominent physical corroboration of the optical and electrical data has been established. This study provides a deterministic approach towards quantifying naphthalene in its solution in terms of its electrical properties. Such study promotes the development of electrical/electronic sensors based on impedance spectroscopy, which would be an excellent tool for sensing hazardous PAHs in terms of robustness, rapidity and cost effectiveness.

\section{Conflicts of interest}

The authors hereby declare that they have no conflict of interest.

Manuscript received: 9/14/18; revised manuscript received: 11/28/18; manuscript accepted: 12/21/18; published online: 1/28/19.

\section{REFERENCES}

1. Jones, O. A.; Lester, J. N.; Voulvoulis, N. Trends Biotechnol., 2005, 23 (4), pp 163-167. doi:10.1016/j.tibtech.2005.02.001

2. Chakraborti, D.; Singh, S.; Rahman, M.; Dutta, R.; Mukherjee, S.; Pati, S.; Kar, P. Int J Environ. Res. Public. Health., 2018, 15 (2), p 180. doi.:10.3390/ijerph15020180

3. Douben, P. E. (Ed.). PAHs: an ecotoxicological perspective. John Wiley \& Sons. 2003.

4. Haque, S.; Mondal, S.; Kundu, D.; Ghosh, A. R. Austin Environ. Sci., 2017, 2, p 1017.

5. Goswami, P.; Ohura, T.; Guruge, K. S.; Yoshioka, M.; Yamanaka, N.; Akiba, M.; Munuswamy, N. Ecotox. Environ. Safe. 2016, 130, pp 113-123. doi:10.1016/j.ecoenv.2016.04.016

6. Abdel-Shafy, H. I.; Mansour, M. S. Egypt. J. Petro., 2016, 25 (1), pp 107-123. doi:10.1016/j.ejpe.2015.03.011

7. Nadal, M.; Schuhmacher, M.; Domingo, J. L. Environ. Pollut., 2004,132 (1), pp 1-11. doi:10.1016/j.envpol.2004.04.003

8. Bihari, N.; Fafand, M.; Hamer, B.; Kralj-Bilen, B. Sci. Total. Environ., 2006, 366 (2-3), pp 602-611. doi:10.1016/j.scitotenv.2005.12.001

9. Cabal, B.; Budinova, T.; Ania, C. O.; Tsyntsarski, B.; Parra, J. B.; Petrova, B. J Hazard Mater., 2009, 161 (2-3), pp 1150-1156. doi.10.1016/j.jhazmat.2008.04.108

10. Armstrong, B.; Hutchinson, E.; Unwin, J.; Fletcher, T. Environ. Health. Persp., 2004, 112 (9), p 970. doi: 10.1289/ehp.6895

11. Ramteke, L. P.; Gogate, P. R. J. Ind. Eng. Chem., 2015, 28, pp 247-260. doi:10.1016/j.jiec.2015.02.022

12. Ghasemi, S.; Nematollahzadeh, A. Adv. Polym. Tech., 2018, 37 (6), pp 2288-2293. doi:10.1002/adv.21904

13. Muñoz, J.; Navarro-Senent, C.; Crivillers, N.; Mas-Torrent, M. Microchim. Acta., 2018, 185 (5), p 255. doi:10.1007/s00604-018-2783-9

14. Reddy, M. S.; Basha, S.; Joshi, H. V.; Ramachandraiah, G. Chemosphere, 2005, 61 (11), pp 15871593. doi:10.1016/j.chemosphere.2005.04.093 
15. Beyer, J.; Aarab, N.; Tandberg, A. H.; Ingvarsdottir, A.; Bamber, S.; Børseth, J. F.; Velvin, R. Mar. Pollut. Bull., 2013, 69 (1-2), pp 28-37. doi:10.1016/j.marpolbul.2013.01.001

16. Vincze, K.; Scheil, V.; Kuch, B.; Köhler, H. R.; Triebskorn, R. Environ. Sci. Pollut. Res., 2015, 22 (15), pp 11822-11839. doi:10.1007/s11356-015-4398-6

17. Bolognesi, C.; Cirillo, S. Curr Zool., 2014, 60 (2), pp 273-284. doi:10.1093/czoolo/60.2.273

18. Muñoz, J.; Crivillers, N.; Mas-Torrent, M. Chem. Eur. J., 2017, 23 (61), pp 15289-15293. doi:10.1002/chem.201703264

19. Qiao, X.; Wei, M.; Tian, D.; Xia, F.; Chen, P.; Zhou, C. J. Electroanal. Chem., 2018, 808, pp 35-40. doi:10.1016/j.jelechem.2017.11.063

20. Dickert, F. L.; Tortschanoff, M.; Bulst, W. E.; Fischerauer, G. Anal. Chem., 1999, 71 (20), pp 45594563. doi:10.1021/ac990513s

21. Chattopadhyay, S.; Chakraborty, S.; Das, C.; Saha, R. Recent Progresses on Micro-and NanoScale Electronic Biosensors: A Review. In Chakraborty, S. Mukherjee, P. (Ed.) Nanospectrum: A Current Scenario, Allied Publisher, India, 2016, pp 19-40.

22. Barman, S. R.; Banerjee, P.; Das, P.; Mukhopadhayay, A. Int. J. Eng. Water Res., 2018, pp 1-13. doi:10.1007/s42108-018-0001-4

23. Chakraborty, S.; Das, C.; Saha, R.; Das, A.; Bera, N. K.; Chattopadhyay, D.; Karmakar, A.; Chattopadhyay, D.; Chattopadhyay, S. J. Electr. Bioimp., 2015, 6, pp 10-17. doi:10.5617/jeb.2363

24. Chakraborty, S.; Das, C.; Bera, N. K.; Chattopadhyay, D.; Karmakar, A.; Chattopadhyay, S. J. Electroanal. Chem., 2017, 784, pp 133 -139. doi:10.1016/j.jelechem.2016.11.055

25. Das, C.; Chakraborty, S.; Acharya, K.; Bera, N. K.; Chattopadhyay, D.; Karmakar, A.; Chattopadhyay, S. Talanta, 2017, 171, pp 327-334. doi:10.1016/j.talanta.2017.05.016

26. Chakraborty, S.; Das, C.; Karmakar, A.; Chattopadhyay, S. Adv. Mater. Proc., 2016, 1, pp 25-31. doi: 10.5185/amp.2016/106

27. Eisenschitz, R.; London, F. Z Phys., 1930, 60, pp 491-527. doi:10.1007/BF01341258

28. Wagner, J. P.; Schreiner, P. R. Angew. Chem., 2015, 127 (42), pp 12446-12471. doi:10.1002/ ange.201503476 